\title{
Percepções de crianças hospitalizadas acerca da contação de histórias
}

\author{
Perceptions of hospitalized children about storytelling \\ Percepciones de los niños hospitalizados sobre la narración de historias \\ Tatiane Vitoria Viana Claudino ${ }^{1}$ (D) https://orcid.org/ 0000-0003-4105-1165 \\ Gabriela Santos Ribeiro de Carvalho ${ }^{1}$ (D) https://orcid.org/ 0000-0002-0145-1052 \\ Cecília Helena de Siqueira Sigaud ${ }^{1}$ (D) https://orcid.org/ 0000-0002-8736-3052
}

\section{Resumo}

Objetivo: Compreender as percepções sobre a contação de histórias na perspectiva de crianças hospitalizadas. Métodos: Pesquisa descritiva de abordagem qualitativa. Após breve contação de histórias, 12 crianças internadas em hospital universitário do município de São Paulo foram entrevistadas e seus depoimentos tratados pelo método de análise de conteúdo de Bardin. Projeto aprovado pelo Comitê de Ética em Pesquisa e autorizado por órgão gestor do serviço hospitalar.

Resultados: Foram identificadas duas categorias principais: "experiências anteriores de contação de histórias" e "experiência hospitalar de contação de histórias". Na primeira categoria todas as crianças relataram experiências prévias de contação de histórias em contexto familiar e escolar. Enquanto na segunda categoria, as crianças relataram ser a primeira vivência dessa atividade em ambiente hospitalar, descrevendo-a como divertida e que possibilitaria minimizar os sentimentos de desconforto e dor.

Conclusão: A contação de histórias promove conforto, alegria e aprendizado à criança hospitalizada, sendo uma atividade absolutamente compatível com a assistência hospitalar.

\begin{abstract}
Objective: Understand the perceptions of storytelling from the perspective of hospitalized children. Methods: After a brief storytelling, 12 children admitted to a university hospital in the city of São Paulo were interviewed and their testimonies were treated by Bardin's content analysis method. Project approved by the Research Ethics Committee and authorized by the hospital service management entity.

Results: Two thematic categories were created "previous storytelling experiences" and "hospital storytelling experience". In the first category, all children reported previous experiences of storytelling in a family and school context. While in the second category, the children reported being the first experience of this activity in a hospital environment, describing it as fun and that would make it possible to minimize the feelings of discomfort and pain. Conclusion: Storytelling promotes comfort, joy and learning for the hospitalized child, being an activity absolutely compatible with hospital care.
\end{abstract}

\section{Resumen}

Objetivo: Comprender las percepciones sobre la narración de historias en perspectiva de los niños hospitalizados. Métodos: Estudio descriptivo de abordaje cualitativo. Luego de una breve narración, se entrevistó a 12 niños ingresados en un hospital universitario de la ciudad de São Paulo y sus testimonios fueron tratados por el método de análisis de contenido de Bardin. Proyecto aprobado por el Comité de Ética en Investigación y autorizado por la entidad gestora del servicio hospitalario.

Resultados: Se identificaron dos categorías principales: "experiencias narrativas previas" y "experiencia narrativa hospitalaria". En la primera categoría, todos los niños relataron experiencias previas de narración de cuentos en un contexto familiar y escolar. En la segunda categoría, los niños informaron que fue la primera experiencia de esta actividad en un ambiente hospitalario, calificandola de divertida y que minimizaría las sensaciones de malestar y dolor.

Conclusión: La narración promueve la comodidad, la alegría y el aprendizaje del niño hospitalizado, siendo una actividad absolutamente compatible con la atención hospitalaria.

\section{Como citar:}

Claudino TV, Carvalho GS, Sigaud CH. Percepções de crianças hospitalizadas acerca da contação de histórias. Rev Soc Bras Enferm Ped. 2021;21(1):22-8.
Descritores

Criança hospitalizada; Enfermagem pediátrica; Narração

Keywords

Child hospitalized; Pediatric nursing; Narration

\section{Descriptores}

Niño hospitalizado; Enfermería pediátrica; Narración

\footnotetext{
${ }^{1}$ Escola de Enfermagem, Universidade de São Paulo, São Paulo, SP, Brasil.

Conflitos de interesse: nada a declarar.

Submetido: 14 de Janeiro de 2021 | Aceito: 30 de Julho de 2021

Autor correspondente: Tatiane Vitoria Viana Claudino | E-mail: tatiane.claudino@usp.br

DOI: http://dx.doi.org/10.31508/1676-3793202100004
} 


\section{Introdução}

Durante a hospitalização, a criança sofre em decorrência da doença e também do próprio processo de hospitalização. Afloram nela diversos sentimentos que abrangem insegurança, medo, ansiedade e angústia, entre outros. ${ }^{(1)}$

O sofrimento da criança hospitalizada resulta de mudanças em sua rotina, bem como de sua inserção em um ambiente estranho e hostil. A separação da mãe, de familiares e amigos também representa uma ameaça. Além disso, ela experimenta perda da autonomia e medo ao ser submetida a procedimentos desconhecidos, desconfortáveis, invasivos e/ou dolorosos. (2) Assim, essa experiência é vivenciada como um evento traumático e estressante pela criança, o que pode contribuir para retardar sua recuperação e favorecer a construção de ideias negativas sobre a hospitalização. (3)

No período de hospitalização, o enfermeiro é um dos profissionais que melhor conhece a criança e seus familiares em razão do extenso tempo e das várias interações que estabelece com eles, quer seja para implementar o tratamento e acompanhar sua evolução, quer seja para ouvi-los e apoiá-los. Assim, apresenta ampla possibilidade de contribuir para a humanização desse cuidado por meio de ações.

Para os profissionais de enfermagem, o cuidado humanizado resulta em aspectos positivos para si e seu trabalho, promovendo crescimento pessoal e profissional, favorecendo a aceitação da assistência pelo paciente e familiares, e intensificando o vínculo entre eles. ${ }^{(3,4)}$

A inserção de atividades lúdicas e recreativas no contexto hospitalar se constitui estratégia valiosa para a humanização do cuidado à saúde infantil, buscando ir além das ações de cuidado, valorizando a escuta, o diálogo e a transformação do espaço formal da assistência a um encontro terapêutico efetivo. ${ }^{(5)} \mathrm{O}$ ato de brincar da criança hospitalizada reflete-se em efeitos benéficos para sua recuperação, visto que é capaz de promover bem-estar ao aliviar sentimentos desagradáveis e estresse vivenciados neste período. É também capaz de proporcionar elementos que fortalecem sua confiança para enfrentar essa situação, minimizando os efeitos adversos da internação. ${ }^{(6)}$

Dentre as atividades lúdicas, encontra-se a contação de histórias. A contação de histórias está presente na cultura humana desde os tempos antigos e é uma das formas encontradas pelo para a transmissão dos conhecimentos e relatos de experiências que trazem lições para gerações futuras, possibilitando a continuidade da evolução humana. ${ }^{(7)}$

É uma atividade terapêutica, que promove a assimilação de valores, significados e conhecimentos, auxilia no desenvolvimento infantil e estimula a participação da criança. Constitui-se meio fundamental para compartilhar experiências e sentimentos, favorecendo a expressão da criança tanto por se identificar com a história que está sendo contada, quanto em decorrência do vínculo estabelecido entre ela e o contador. ${ }^{(4)}$ No contexto da hospitalização infantil, a contação de histórias pode contribuir para o oferecimento de diversão, a diminuição das tensões e ansiedades, o alívio da dor e o estabelecimento de confiança. ${ }^{(8)}$

Na literatura, há escassez de estudos relativos à utilização de contação de histórias durante a hospitalização infantil e, em especial, das percepções das crianças sobre essa prática. Diante do exposto, esse trabalho tem como objetivo compreender as percepções sobre a contação de histórias na perspectiva de crianças hospitalizadas.

\section{Métodos}

Estudo descritivo de abordagem qualitativa, ${ }^{(9)}$ realizado com crianças em idade pré-escolar e escolar hospitalizadas em unidade pediátrica de hospital universitário de nível secundário da cidade de São Paulo-SP, Brasil.

Os critérios de inclusão para participar da pesquisa foram: criança hospitalizada por no mínimo dois dias; idade infantil entre 4 e 13 anos incompletos, assumindo que, a partir dos 4 anos de idade, a linguagem oral encontra-se mais estruturada, o vocabulário mais ampliado e a criança possui maior capacidade de expressar suas experiências e pensamentos verbalmente, apresentando melhores condições para participar de entrevista; acompanhada por responsável legal; criança e responsável em condições psíquicas para a interação e com interesse em ouvir histórias e conversar, com capacidade cognitiva preservada. Recusaram-se a participar da pesquisa 6 crianças de 5 a 13 anos, pelos seguintes motivos: alta hospitalar, desinteresse, presença de dor e sonolência após procedimento cirúrgico. 
No trabalho de campo, para cada criança e acompanhante, as pesquisadoras realizaram a contação de 2 a 4 histórias, em tempo médio de 16 minutos no total, à beira leito ou no espaço da brinquedoteca da unidade. Para tanto, foram selecionadas e treinadas a contação de dez histórias, que continham mensagens de otimismo, esperança, amizade, amor, em contextos lúdicos, envolvendo animais, plantas, pessoas e personagens mágicos e fantasiosos. Os contos e fábulas escolhidos foram: "O rei com orelhas de burro", "A princesa e a ervilha", "A sopa de pedra", "Os três cabritinhos", "A astúcia de Nasrudin", "O banho de Nasrudin", "O casamento da princesa", "O casamento de sir Gawain e dama Ragnell", "O pequeno grão de areia" e "A cidade dos carregadores de pedra".

Para a coleta de dados, logo após a contação de histórias, as pesquisadoras realizaram entrevista semiestruturada e individual com as crianças na presença dos familiares, mediante sua anuência e assinatura do Termo de Assentimento Livre e Esclarecido (TALE) e do Termo de Consentimento Livre e Esclarecido (TCLE) pelo responsável. Para as entrevistas, foi utilizado roteiro voltado à exploração de tópicos relativos às experiências anteriores e a atual (durante hospitalização) de contação de histórias, com tempo médio de 6 minutos de duração, durante os meses de abril e maio de 2019. Os depoimentos foram gravados com a autorização das crianças e seus responsáveis.

Observou-se que as crianças mais jovens, de 4 a 7 anos, apresentaram menor desenvoltura ao expressar-se verbalmente, resultando em entrevistas mais breves. Não se aplicou qualquer pressão sobre elas, permitindo discorrer livremente sobre a experiência de contação de histórias.

Para a análise dos dados, foi realizada análise temática de conteúdo do material, proposta por Bardin. Esse método consiste em três etapas: a) pré-análise - transcrição e organização do material obtido nas entrevistas constituindo o corpus, seguida pela leitura flutuante do mesmo; b) exploração do material - extração de núcleos de significado (unidades de registro) do corpus, codificação, classificação e agregação, dando origem às categorias teóricas; c) tratamento dos resultados e interpretação - por meio da observação à frequência de repetições das categorias e da comparação das mesmas ao quadro teórico de referência, procede-se à interpretação através do estabelecimento de relações entre elas e do desvelamento do conteúdo latente das comunicações com vistas à proposição de inferências. ${ }^{(10)}$

O projeto de pesquisa foi aprovado por Comitê de Ética em Pesquisa e autorizado por órgão gestor do serviço hospitalar (Parecer $\mathrm{n}^{\mathrm{o}} 3.148 .511$ ), conforme a Resolução nº 466/12. ${ }^{(11)}$

\section{Resultados}

Participaram do estudo doze crianças hospitalizadas. A título de caracterizá-las, havia sete do sexo feminino e cinco do masculino, com idade entre quatro e treze anos. Onze frequentavam a escola. Em relação ao parentesco dos acompanhantes, oito crianças se encontravam com suas mães, três com seus pais e uma com a avó materna. No momento da contação de histórias e entrevista, as crianças estavam entre o segundo e décimo quinto dia de internação. Metade das crianças já tinham vivenciado processo de hospitalização anterior. Os depoimentos coletados foram organizados em duas categorias temáticas principais, quais sejam: "Experiências anteriores de contação de histórias" e "Experiência hospitalar de contação de histórias". Visando a confidencialidade da identidade dos participantes, seus nomes foram codificados conforme as letras do alfabeto de A a L, de modo aleatório, as quais serão apresentadas seguidas das idades das crianças, após os exemplos extraídos das entrevistas.

\section{Categoria "Experiências anteriores de contação de histórias"}

Nessa categoria são apresentadas as experiências de contação de histórias vivenciadas fora do espaço hospitalar, descrevendo-se o contexto em que ocorreram, o narrador, os sentimentos produzidos e o tipo de histórias. Todas as crianças relataram ter tido experiências anteriores de contação de histórias em sua vida. Essas experiências aconteceram predominantemente em contexto familiar e escolar. Apenas uma das crianças menciona uma experiência em ambiente de lazer público, um parque.

\footnotetext{
"Em casa." (H, 7 anos)

"Na escola." (I, 7 anos)
} 
"Estava na escola, em casa e também no parque." (E, 12 anos)

Quando em contexto familiar, as mães, irmãs, avós e primo foram os narradores lembrados, sendo a mãe o principal deles, citada por todos os entrevistados, indicando um forte vínculo feminino a essa prática.

\footnotetext{
"Em casa, a minha mãe conta..." ( $A, 5$ anos)

"Na maioria das vezes minha irmã mais velha, olhando os livros..." ( $F, 8$ anos)

"Ah, minha mãe já (contou) algumas vezes e minha avó." (J, 10 anos)

"Meu primo, ele me contou uma história que ouviu na escola." ( $C, 7$ anos)
}

As escolas também assumem um papel importante na contação de histórias, sendo as professoras o agente responsável lembrado por vários entrevistados.

"Sim, (a professora conta) todo dia. Professora de português." (I, 7 anos)

"Minha professora e minha mãe." (H, 7 anos)

"Professora." ( $A, 5$ anos)

Todas as crianças apreciaram suas experiências pregressas de contação de histórias, referindo sentimentos de satisfação, prazer, alegria e felicidade.

"Às vezes, por exemplo, me senti feliz por ter ouvido uma história conhecida." ( $F, 8$ anos)

"Não sou bom em palavras, só sei que me sentia bem. (...) Gostei, lembro delas (das histórias) até hoje." ( $D, 13$ anos)

"Eu me senti alegre." ( $C, 7$ anos)

Elas explicam sua satisfação com as histórias por diversos motivos, dentre eles por serem engraçadas, divertidas, propiciarem o riso e felicidade, trazerem relaxamento e conforto, favorecerem o adormecimento, levantarem a autoestima fazendo com que a criança se sentisse mais animada e feliz.

"Porque era divertida e algumas fazem eu rir." (C, 7 anos)

"Legal, me fazia dormir, quando era a hora de dormir. E me deixava relaxado." (D, 13 anos)
"Distraí um pouco. Tipo, se você está com um pensamento ruim, daí ele conta história e você já fica mais animado, levanta a autoestima. Eu fiquei muito feliz." (E, 12 anos)

Algumas crianças mencionaram o tipo de história que apreciavam, destacando os contos de fadas, as histórias com personagens femininas de referência atual e as fábulas, apenas uma criança mencionou uma história de escritor nacional, evidenciando que são privilegiadas as clássicas e estrangeiras.

"Já contou [mãe] do cachorrinho, da branca de neve e da princesa." ( $A, 5$ anos)

"De um monte de coisa, de princesa, de Barbie, de monster high. [...] A da bela adormecida... da princesa... minha mãe que contou." ( $D, 13$ anos)

"Minha mãe contou de princesa e a professora de outra princesa." (B, 6 anos)

"Contos de fadas: chapeuzinho vermelho, a branca de neve e os sete anões, cinderela, a princesa e a ervilha, os sete cabritinhos..." (E, 12 anos)

"Já [a professora] tinha do menino maluquinho, a sopa de pedra e a feiurinha." (C, 7 anos)

\section{Categoria "Experiência hospitalar de contação de histórias"}

Descreve-se, neste categoria, como ocorreu a experiência de contação de histórias no contexto hospitalar, indicando o narrador, os sentimentos e suas preferências em relação às histórias.

De forma geral as crianças negaram ter tido experiências anteriores de contação de histórias em contexto hospitalar, exceto uma que a vivenciou no atual período de internação. Nesse caso em particular, a contação foi realizada por profissional da equipe de enfermagem.

"Já. A enfermeira (contou) uma história do livrinho do meu quarto." ( J, 10 anos)

Quanto à contação de histórias realizada pelas pesquisadoras, foi vivenciada positivamente por todas as crianças. Observou-se que apreciaram a intervenção, descrita como experiência prazerosa e divertida, 
que promoveu sentimentos de bem-estar, felicidade e alegria, minimizando desconfortos e dor.

"Eu (me) senti muito bem, porque eu fico muito animada de ouvir história." ( $B, 6$ anos)

"Bem legal. Eu me senti bem alegre. Bem, bem, bem alegre. Eu gostei de todas." (C, 7 anos)

"Sim, eu gostei muito das histórias de hoje. Me deixou mais feliz." ( $D, 13$ anos)

"Me senti bem, até parou um pouquinho de doer o pé. Achei bem legal contar histórias para as crianças no hospital." (E, 12 anos)

"É um passatempo muito legal para as crianças que ouvem elas. Elas vão gostar, vão é... como posso dizer... vão se abrir mais. Para mim, ouvir outras histórias é muito bom. Eu passo aquele tempo feliz, imaginando a felicidade." ( $F, 8$ anos)

As histórias contadas também contribuíram para o aprendizado enriquecendo as experiências e conhecimentos das crianças de forma agradável. Essa experiência positiva despertou o interesse por outras oportunidades de leitura.

"Porque tem um monte de coisa que eu não sabia." (B, 6 anos)

"Ah, eu achava que história assim era coisa de criança, mas agora eu vi que é bem legal. Acho que vou tentar ler mais histórias." ( $D, 13$ anos)

Em geral, as meninas preferiram ouvir histórias de princesas do gênero dos contos de fadas, enquanto os meninos se interessaram por histórias engraçadas e aventureiras.

As crianças interagiram com as pesquisadoras no momento da contação, principalmente as menores, sendo estimuladas a participar da atividade. Elas contribuíram ao agregar novos elementos aos personagens e às histórias, ao tentar adivinhar o final ou propor um desfecho alternativo. Algumas vezes, chegaram a acrescentar novos personagens às histórias.

"Ele (o personagem Nasrudin) é bem inteligente, certeza que vai ficar com várias moedas." (D, 13 anos)

"A bruxa, ela é malvada. (criança sugeriu:) Ela virava do bem aí ficava mais legal, que ela brincava com os carneirinhos." ( $J$, 10 anos)
"Hummmm... da bruxa, eu não gostei. Porque ela é feia." ( $L, 4$ anos)

As crianças também manifestaram suas percepções sobre as histórias, destacando as características mais marcantes e significativas acerca dos personagens, como a coragem, a força, a esperteza e a graça.

"Porque os carneirinhos tentam passar e a bruxa não deixa. Mas, quando chega o carneirinho mais velho, a bruxa vai enfrentar ele e ele joga ela no rio. O carneirinho tenta enfrentar ela." ( $E, 12$ anos)

"(A história ) Do dinheiro. Achei engraçada e ele foi esperto." ( $C, 7$ anos)

"Ela (a cabeleireira) conta o segredo para árvore. $(O$ lenhador derruba a árvore) quando faz o violão com a árvore. Daí (o violão) conta o segredo (para todos). Daí, achei engraçado." (E, 12 anos)

"Das duas histórias a parte que eu mais gostei [...] Foi a parte que o irmão mais velho do cabritinho mostrou que a... falou que era mais corajoso, falou que tinha aquela coragem pra parar a bruxa." ( $F, 8$ anos)

\section{Discussão}

A entrevista, como técnica de coleta de dados, representou uma limitação desta investigação em relação às crianças pré-escolares, que não possuíam linguagem verbal tão bem desenvolvida, resultando em depoimentos breves e empobrecidos. Com esse grupo infantil, buscou-se adotar uma linguagem simples e adequada para a faixa etária, deixando-as se comunicarem de maneira livre e sem pressão. Considera-se que a referida limitação não comprometeu o alcance do objetivo do estudo.

Contar histórias é uma prática antiga exercida há séculos, que transmite conhecimentos de uma geração para outra e constitui-se um meio para a perpetuação das tradições. É uma forma de expressão utilizada pelo ser humano na transmissão do seu pensamento, ideias e percepções. ${ }^{(12)}$

Desde os primórdios, a comunicação verbal através das histórias e imagens precede os textos e a linguagem escrita. O ser humano é capaz de criar histórias sobre diversos assuntos, sendo uma ferramenta para se comunicar antes mesmo de aprender a ler e 
escrever. A contação de histórias provoca um contato com o mundo da imaginação e da criação, sendo alicerce para a compreensão de mundo, despertando sentimentos, afetos e emoções. ${ }^{(13)}$ A participação ativa das crianças neste estudo ao proporem mudanças no enredo ou no desfecho das histórias, revela seu potencial de estímulo à criatividade e imaginação infantil, e oportunidade e liberdade de expressão de ideias.

A pesquisa revelou que a contação de histórias já estava presente no cotidiano das crianças no ambiente familiar e escolar. Entende-se que a contação de histórias é uma estratégia que favorece de maneira significativa a prática docente, uma vez que estimula a imaginação, instrui, desenvolve habilidades cognitivas e potencializa a linguagem infantil. Enquanto se diverte, através das narrativas a criança aprende novos vocabulários e desenvolve habilidade linguística em nível oral e escrito, favorecendo o processo de escrita e leitura, e estimulando o prazer por ambas. ${ }^{(14)}$

A contação de histórias também desenvolve o senso crítico e a capacidade de enfrentamento de problemas, ao oferecer exemplos criativos de superação. Ao ouvir histórias a criança tem a oportunidade de ampliar sua compreensão de mundo, fazer comparações e assimilar diferenças. Tem contato com outras realidades diferentes da sua. ${ }^{(15)}$

Outro aspecto positivo relacionado à contação de histórias diz respeito ao apoio à experiência emocional vivenciada pela criança no processo de hospitalização. As crianças não possuem estratégias sofisticadas para lidar com sentimentos difíceis e intensos. Elas possuem poucos recursos internos para compreendê-los completamente e regular a intensidade dos mesmos, podendo ter consequências dolorosas em seu desenvolvimento. Dessa forma, a contação de histórias pode proporcionar oportunidade para a criança identificar e lidar com seus sentimentos ao se utilizar de uma linguagem metafórica, acessível e apropriada à ela. Os elementos contidos nas histórias podem permitir a elaboração de conflitos por parte das crianças, retratados em realidades muito distintas e fantasiosas. ${ }^{(16)}$

A ferramenta de contação de histórias reconhece a limitação das crianças na expressão de seus sentimentos na linguagem cotidiana. Para elas, a linguagem natural do sentimento é a da imagem e da metáfora como em fantasias e sonhos. Através da contação de histórias a utilização dessa técnica possibilita abordar as crianças num nível mais profundo e imediato do que a linguagem literal, podendo funcionar como um ingresso no mundo interior da criança e permitindo-lhe compreender sentimentos de conflito. ${ }^{(17)}$

A história oferece à criança mecanismos que ela pode utilizar para enfrentar seus conflitos internos. A afeição por personagens fortes pode trazer conforto e uma mensagem de esperança à criança hospitalizada, devido à longa jornada de superação enfrentada. ${ }^{(17)}$ Nos depoimentos das crianças entrevistadas são enfatizadas tais características dos personagens, de força, persistência e coragem, destacando-os como uma fonte de esperança e inspiração.

A contação de histórias é também uma atividade que promove a socialização. ${ }^{(15)} \mathrm{O}$ desenvolvimento infantil ocorre na interação da criança com o meio, estimulando-a a viver a experiência. ${ }^{(18)}$ A maneira como as histórias foram contadas para as crianças, em que se procurou incentivar sua participação, foi uma estratégia utilizada pelas pesquisadoras para incluí-las na atividade, envolvendo-as de modo a fomentar sua imaginação tornando-a mais divertida e interessante.

Ainda hoje em nossa sociedade a mulher é a principal responsável pelas atividades domésticas e cuidados com a família, possuindo maior proximidade com os filhos e participando ativamente de sua criação. ${ }^{(19)}$ Tal fato explica o protagonismo feminino ligado à atividade de contação de histórias no espaço da família. No contexto escolar, principalmente no da educação infantil, também se observa maior quantitativo de mulheres entre os educadores, justificando a menção às professoras. ${ }^{(20)}$

\section{Considerações finais}

Os objetivos propostos para o estudo foram alcançados, revelando uma percepção positiva das crianças em relação à contação de histórias durante o processo de hospitalização. A contação de histórias se mostrou uma atividade lúdica capaz de promover aprendizado, desenvolvimento, conforto, relaxamento, divertimento, alegria, bem-estar e alívio do estresse vivenciado pelas crianças hospitalizadas e seus familiares, revelando-se interessante e benéfica. A inclusão de intervenções terapêuticas diferenciadas e apropriadas às crianças, que levam em conta as características do desenvolvimento infantil, como é o caso da contação de histórias, é fun- 
damental para a humanização da assistência à saúde. Essa prática demonstrou ser uma valiosa ferramenta para a abordagem às crianças, uma vez que se integra ao universo infantil, favorecendo, assim, sua recuperação. Outro aspecto relevante a destacar diz respeito ao ganho indireto obtido pela instituição hospitalar e profissionais que nela atuam, uma vez que, ao promover o conforto e bem-estar da criança, a contação de histórias alivia as tensões e facilita o relacionamento com a equipe de saúde durante a vivência da hospitalização. O presente estudo revelou que essa estratégia é compatível com a assistência à saúde da criança, considerando que demanda curto período de tempo e se ajusta a diferentes ambientes, como enfermaria e brinquedoteca, sem exigir materiais especiais. A capacitação do profissional para a prática de contação de histórias é o único requisito para assegurar a adequada abordagem à criança, a escolha das histórias e o uso apropriado da linguagem. Sendo assim, todos os profissionais de saúde podem incorporá-la a sua atuação, bastando para isso capacitar-se. A relevância dos resultados indica a necessidade do desenvolvimento de novas pesquisas para o aprofundamento dos conhecimentos sobre a temática em questão. Nesse estudo, encontraram-se limitações relativas à linguagem verbal pouco desenvolvida entre as crianças de 4 a 6 anos.

\section{Agradecimentos}

Projeto Financiado pela Pró-Reitoria de Graduação da Universidade de São Paulo, através do Programa de Unificado de Bolsas (PUB), Edital 2018-2019, pelo apoio na forma de bolsa de iniciação científica à estudante de enfermagem Tatiane Vitoria Viana Claudino e na forma de bolsa à atividade de cultura e extensão universitária à estudante de enfermagem Gabriela Santos Ribeiro de Carvalho.

\section{Contribuições}

Claudino TVV, Carvalho GSR e Sigaud CHS declaram que contribuíram com a concepção do estudo, análise e interpretação dos dados, redação do artigo, revisão crítica relevante do conteúdo intelectual e aprovação da versão final a ser publicada.

\section{Referências}

1. Gesteira EC, Franco EC, Braga PP, Criscuolo MB, Oliveira JS. Contos infanto-juvenis: uma prática lúdica de humanização para crianças hospitalizadas. Rev Enferm UFSM. 2014;4(3):575-83.

2. SimõesAL, Maruxo HB, Yamamoto LR, Silva LC, Silva PA. Satisfação de clientes hospitalizados em relação às atividades lúdicas desenvolvidas por estudantes universitários. Rev Eletrônica Enferm. 2010;12(1):107-12.

3. Paula GK, Góes FG, Silva AC, Moraes JR, Silva LF, Silva MA. Estratégias lúdicas no cuidado de enfermagem à criança hospitalizada. Rev Enferm UFPE on line. 2019;13:e238979.

4. Knoche LM. Contar, ler e brincar: a importância da contação e da leitura de histórias aliadas ao lúdico como agentes transformadores da rotina hospitalar. Rev ACB. 2013;18(1):57698.

5. Ceribelli C, Nascimento LC, Pacífico SM, Lima RA. A mediação de leitura como recurso de comunicação com crianças hospitalizadas. Rev Latino-Am Enfermagem. 2009;17(1):81-5.

6. Araújo RA, Silva FA, FaroA, Sobral AL. Uso de atividades lúdicas no processo de humanização em ambiente hospitalar pediátrico: intervenção Programa de Educação pelo Trabalho para a Saúde (PET/Saúde REDES - Urgência e Emergência). Rev SBPH. 2016;19(2):98-106.

7. Garcia-Schinzari NR, Pfeifer LI, Sposito AM, Santos JLF, Nascimento LC, Panúncio-Pinto MP. Caixas de histórias como estratégia auxiliar do enfrentamento da hospitalização de crianças e adolescentes com câncer. Cad Ter 0cup UFSCar. 2014;22(3):569-77.

8. Brondani JP, Wegner W. A contação de histórias como tecnologia na promoção da autonomia e participação da criança hospitalizada no cuidado de enfermagem. J Nurs Health. 2019;9(3):e199311.

9. Gil AC. Métodos e técnicas de pesquisa social. 7a ed. São Paulo: Atlas; 2019.

10. Minayo MC. 0 desafio do conhecimento: pesquisa qualitativa em saúde. 11a ed. São Paulo: Hucitec; 2014

11. Brasil. Ministério da Saúde. Conselho Nacional de Saúde. Resolução n. 196, de 10 de outubro de 1996. Aprova as diretrizes e normas regulamentadoras de pesquisas envolvendo seres humanos. Diário Oficial da República Federativa do Basil, Brasília (DF); 1996 Out 16

12. Horta AL, Camargo MZ, Cruz MG, Daspett C. Contando histórias familiares: estratégias de aprendizagem no cuidado com família. Acta Paul Enferm. 2012;25(2):128-33.

13. Barbosa EB, Voltarelli MA. Participação das crianças em projeto político-social elaborado por adultos: a Plenarinha no Distrito Federal. Educ Pesqui. 2020;46:e236680.

14. Souza LO, Bernardino AD.A contação de histórias como estratégia pedagógica na educação infantil e ensino fundamental. Educere Educ. 2011;6(12):235-49.

15. Sousa JP. Contação de história: contribuição para 0 desenvolvimento da socialização e aprendizagem de crianças da educação infantil [monografia]. João Pessoa: Universidade Federal da Paraíba; 2014.

16. Sunderland M. 0 valor terapêutico de contar histórias: para crianças, pelas crianças. 3a ed. São Paulo: Cultrix; 2012. p.15-30.

17. Silva AC, Sei MB. A contação de histórias e a humanização no hospital: vivências de profissionais da saúde. Rev SBPH. 2019;22(2):68-89

18. Belancieri MF, Rodrigues KR, Capellini VL, Reis VL. Pedagogia hospitalar: intervenções na unidade pediátrica a partir da contação de histórias. Semin Ciênc Soc Hum. 2018;39(1):53-64

19. Guedes OS, Daros MA. 0 cuidado como atribuição feminina: contribuições para um debate ético. Serv Soc Rev. 2009;12(1):122-34.

20. Moura JF. A feminização da docência na educação infantil da rede municipal de ensino de Imperatriz: uma discussão panorâmica. InterEspaço. 2016;2(5):490-513. 